\title{
One-Pot Synthesis of 1-[(Triisopropylsilyl)ethynyl]-1,2-benziodoxol- $3(1 H)$-one (TIPS-EBX): Process Safety Assessment and Impact of Impurities on Product Stability
}

\author{
Durga Prasad Hari, ${ }^{\dagger}$ Paola Caramenti, ${ }^{\dagger}$ Lionel Schouwey, ${ }^{\dagger}$ Miyeon Chang, ${ }^{\dagger}$ Stefano Nicolai, ${ }^{\dagger}$ \\ Donald Bachert, ${ }^{*}$ Timothy Wright, ${ }^{\ddagger}$ Chuck Orella, ${ }^{*}$ and Jerome Waser*, ${ }^{*}$ (e) \\ ${ }^{\dagger}$ Laboratory of Catalysis and Organic Synthesis, Ecole Polytechnique Fedérale de Lausanne, EPFL SB ISIC LCSO, BCH 4306,1015 \\ Lausanne, Switzerland \\ ${ }^{\ddagger}$ Chemical Engineering R\&D, Merck \& Co., Inc., Rahway, New Jersey 07065, United States
}

Supporting Information

\begin{abstract}
The hypervalent iodine reagent 1[(TriIsoPropylSilyl)Ethynyl]-1,2-BenziodoXol-3(1H)-one (TIPS-EBX) is among the most useful electrophilic and somophilic alkynylation reagents. Herein, we report a new synthetic protocol to access this reagent in one step from standard commercially available reagents. Thermal analysis of the synthesis procedure showed only weak exotherms. The compound could be obtained with high purity and stability using this new protocol, but care had to be taken to remove tosylate salts impurities, as they led to a lower thermal stability. TIPS-EBX synthesized using the new procedure displayed no shock sensitivity.
\end{abstract}

KEYWORDS: alkynylation, hypervalent iodine reagents, acetylene, EBX, stability

T ypervalent iodine reagents have fascinated chemists since 1 their discovery by Willgerodt in the 19th century. ${ }^{1}$ In the past 50 years, these compounds have risen from structural curiosities to one of the most useful classes of reagents for synthetic organic transformations. ${ }^{2}$ The hypervalent bonds at the core of their structure are weak, conferring them with exceptional reactivity. Whereas having reactive bonds is a unique advantage to promote synthetic transformations under mild conditions, these reagents need to be manipulated with care to avoid exothermic decomposition or even explosion. In this respect, cyclic hypervalent iodine reagents are interesting, due to their enhanced stability. ${ }^{3,4}$ Our group in particular demonstrated the exceptional properties of ethynylbenziodoxolone (EBX) reagents, first discovered by Ochiai and Zhdankin, ${ }^{5,6}$ for the alkynylation of nucleophiles. ${ }^{7}$ Currently, these reagents are used broadly for the introduction of alkynes in direct or transition-metal-catalyzed reactions, as well as in radical-based processes. The most applied reagent is the silylated derivative 1-[(triisopropylsilyl)ethynyl]-1,2-benziodoxol-3(1H)-one (TIPS-EBX) (1), which has been used in diverse transformations such as metal-catalyzed $\mathrm{C}-\mathrm{H}$ functionalization, ${ }^{8-11}$ palladium-catalyzed oxy- and aminoalkynylation of olefins, ${ }^{12}$ reaction with simple heteroatom or carbon nucleophiles, ${ }^{13-15}$ and reaction with radical $^{16,17}$ or metal-carbene ${ }^{18}$ intermediates (Scheme 1). This success can be tentatively assigned to three main factors: (1) TIPS-EBX
Scheme 1. Synthetic Applications of TIPS-EBX (1)

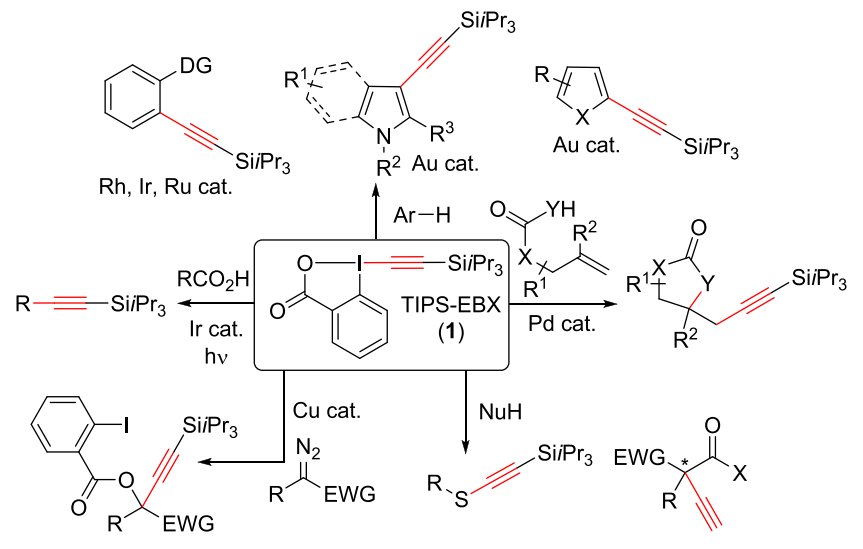

(1) can be accessed in high yield using simple synthetic protocols; (2) the large silyl protecting group shields the triple bond, limiting side reactions in numerous processes; and (3) versatile terminal acetylenes can be easily accessed after silyl deprotection.

Nevertheless, stability studies on TIPS-EBX (1) have been limited to our own work using DSC calorimetry. ${ }^{19}$ The synthesis most often used is still the robust two-step protocol developed by Zhdankin and co-workers ${ }^{6}$ and scaled-up by our group, ${ }^{20}$ involving first the oxidation of 2 -iodobenzoic acid (2) with sodium periodate to give hydroxybenziodoxolone (3) in $81 \%$ yield, followed by reaction with trimethylsilyltriisopropylsilyl acetylene (4a) after activation with trimethylsilyl triflate to give TIPS-EBX (1) in $85 \%$ yield (Scheme 2A). In 2012, Olofsson and co-workers reported an alternative one-step protocol based on in situ oxidation of 2-iodobenzoic acid (2) with meta-chloroperbenzoic acid ( $m \mathrm{CPBA})$ to give $\mathbf{1}$ in $85 \%$ yield (Scheme $2 \mathrm{~B}$ ). ${ }^{21}$ However, this protocol required the use of noncommercial and sensitive alkynyl boronic ester $\mathbf{4 b}$.

Herein, we report a modified one-pot synthesis of TIPS-EBX (1) inspired by Olofsson's work based on the use of commercially available 2 -iodobenzoic acid (2) and triisopropylsilyl acetylene $(4 \mathrm{c})$ with $m \mathrm{CPBA}$ as the oxidant and para-

Received: November 18, 2019

Published: December 24, 2019 


\section{Scheme 2. Synthesis of TIPS-EBX (1)}

A) Zhdankin's two-step procedure

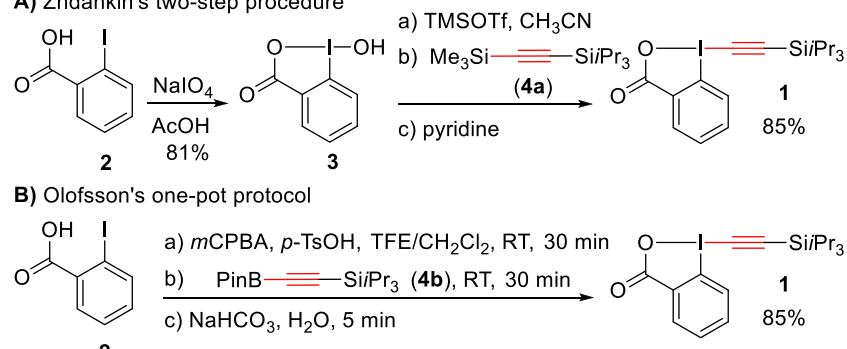

C) This work: one-pot protocol directly from triisopropylsilylacetylene (4c)

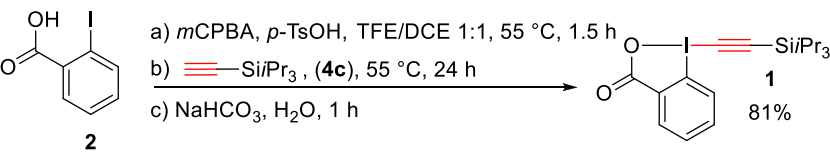

toluene sulfonic acid as the activator. The reaction proceeds smoothly on multigram scale to give TIPS-EBX (1) in $>80 \%$ yield. Calorimetric analysis of the process showed no strong exotherm. Care had to be taken to completely remove traces of tosylate salts, as these impurities diminish the thermal stability of TIPS-EBX (1).

In our hands, the Zhdankin's protocol for the synthesis of TIPS-EBX $(\mathbf{1})^{6}$ has proven highly scalable and reliable. ${ }^{20}$ Nevertheless, three separate steps are still required: Oxidation of the hypervalent iodine, preparation of trimethylsilyltriisopropylsilylacetylene (4a), and alkyne transfer. The method developed by Olofsson and co-workers was attractive, as in situ oxidation with isolation of an iodine(III) precursor became possible. ${ }^{21}$ However, the used alkynyl boronic ester $\mathbf{4 b}$ is difficult to synthesize and purify. We therefore wondered if commercially available triisopropylacetylene could be used directly in the Olofsson protocol. However, only a very low yield of TIPS-EBX (1) could be isolated using the reported reaction conditions ( $\mathrm{rt}, 30 \mathrm{~min}$ for alkyne transfer). The lower reactivity observed was probably due to a lower nucleophilicity of the terminal alkyne in the key reagent forming step. Gratifyingly, replacing dichloromethane by 1,2-dichloroethane and performing the reaction at $55{ }^{\circ} \mathrm{C}$ for $24 \mathrm{~h}$ led to full alkyne transfer (Scheme 2C). At higher temperature, decomposition of the reagent can occur. The oxidation step was also conveniently run at the same temperature, after addition of $m \mathrm{CBPA}$ and para-toluenesulfonic acid $(p-\mathrm{TsOH})$ at room temperature. The cyclization step can be easily performed by just stirring the crude reaction mixture with a bicarbonate solution, avoiding the potentially hazardous removal of solvents prior to basification. The resulting protocol is highly convenient, as only commercially available starting materials can be used without further purification $(p-\mathrm{TsOH}$ can be used in its monohydrate form, and safe commercial $\leq 77 \%$ pure $m$ CPBA also works well). ${ }^{22}$

With an optimized protocol in hand, we examined the heats of reaction in the three different steps of the reaction (Table 1, entries 1-3). At the concentrations used the desired heats of reaction produce moderate exotherms for the oxidation and the cyclization step (entries 1 and 3 ), corresponding to an adiabatic temperature rise that is smaller than $15{ }^{\circ} \mathrm{C}$. No exotherm was observed for the reaction of the oxidized intermediate with the terminal alkyne 4c (entry 2).

Next the stability of the obtained TIPS-EBX (1) was examined by DSC. However, a batch-to-batch dependency was
Table 1. Heat of Reactions for the Preparation of TIPS-EBX (1)

$\begin{array}{ccccc}\text { Entry } & \text { Reaction } & \begin{array}{c}\text { Molar } \\ \text { enthalpy } \\ (\mathrm{kJ} / \mathrm{mol})\end{array} & \begin{array}{c}\text { Specific } \\ \text { enthalpy } \\ (\mathrm{kJ} / \mathrm{kg})\end{array} & \begin{array}{c}\text { Adiabatic } \\ \text { Temperature Rise } \\ (\mathrm{K})\end{array} \\ 1 & \begin{array}{c}\text { mCPBA } \\ \text { Oxidation }\end{array} & 105 & 424 & 11 \\ 2 & \begin{array}{c}\text { TIPS-Alkyne } \\ \text { Coupling }\end{array} & -1 & -2 & 0 \\ 3 & \begin{array}{c}\text { Cyclization } \\ { }^{a} \text { Relative to limiting reagent. }\end{array}{ }^{b} \text { Relative to actual reagent. }\end{array}$

observed, with decomposition starting from $100{ }^{\circ} \mathrm{C}$ (DSC A in Figure 1) to $140{ }^{\circ} \mathrm{C}$. With the least stable sample, no melting point could be observed any more. ${ }^{1} \mathrm{H}$ NMR was used to evaluate the purity of the sample with the lower decomposition temperature, which was about $92 \%$ pure, as shown in spectra A of Figure 2. The impurities were consistent with residual $p$ toluenesulfonate. Since the workup includes a bicarbonate wash and the $\mathrm{pH}$ was not acidic, we believe that this was the sodium salt of $p$-TsOH. Subsequently, a sample of $\mathbf{A}$ was dissolved/suspended in DCM and washed three times with water prior to solvent removal. Gratifyingly, the purity improved to almost $98 \%$ by NMR (Spectra B, Figure 2) and the onset of the decomposition temperature increased to 131 ${ }^{\circ} \mathrm{C}$ (DSC B, Figure 1). A melting point was observed at 115 ${ }^{\circ} \mathrm{C}$. To further improve the purity, a sample of $\mathbf{A}$ was redissolved in dichloromethane and washed again three times with water, and the product was obtained by precipitation through addition of acetonitrile after filtration of the solution. These solids had a purity above $99 \%$ by ${ }^{1} \mathrm{H}$ NMR (Spectra C, Figure 2), and the onset of decomposition occurred now at $144{ }^{\circ} \mathrm{C}$ (DSC C, Figure 1).

A commercial sample purchased from Sigma-Aldrich showed comparable NMR purity (Spectra D, Figure 2). The melting point was now identical, but the decomposition onset was still higher $\left(161{ }^{\circ} \mathrm{C}\right.$, DSC D, Figure 1). When the synthesis protocol with three water washes, but using a purification by recrystallization in acetonitrile, and the DSC analysis were repeated in another laboratory, ${ }^{23}$ similar melting points and decomposition onset temperatures (125 and $136{ }^{\circ} \mathrm{C}$ respectively, see Figure $\mathrm{S} 1$ in SI) as well as purity by ${ }^{1} \mathrm{H}$ NMR were observed (see Figure S2 in SI). The DSC analysis performed on TIPS-EBX (1) synthesized via Zhdankin's protocol also displayed similar data in our previous work $\left(112\right.$ and $\left.136{ }^{\circ} \mathrm{C}\right) .{ }^{19}$ In order to test the stability of TIPS-EBX (1) upon storage, DSC was utilized to again measure a sample after 4 months of storage at $-20{ }^{\circ} \mathrm{C}$. No significant difference was observed for neither the sample synthesized using the new protocol nor the commercially available compound from Sigma-Aldrich (see Figures S3 and S4 in SI). An overview of the different DSC results is given in Table 2. The relationship between purity and decomposition temperature is clearly apparent.

Note that the DSC analysis included single experiments in screening mode carried out at $5{ }^{\circ} \mathrm{C} / \mathrm{min}$. For higher accuracy, DSC can be run at several scan rates as slowly as 0.5 to $1^{\circ} \mathrm{C} /$ min or preferably adiabatic calorimetry is carried out at gram scale. Such DSC repeats will improve the precision of the melting point and will also show a transition in the onset temperature, with a slower heating rate showing lower onset. The shift in onset temperature reflects more time for the reaction to reach a measurable temperature rise with increased 
Differential Scanning Calorimetry Thermograms

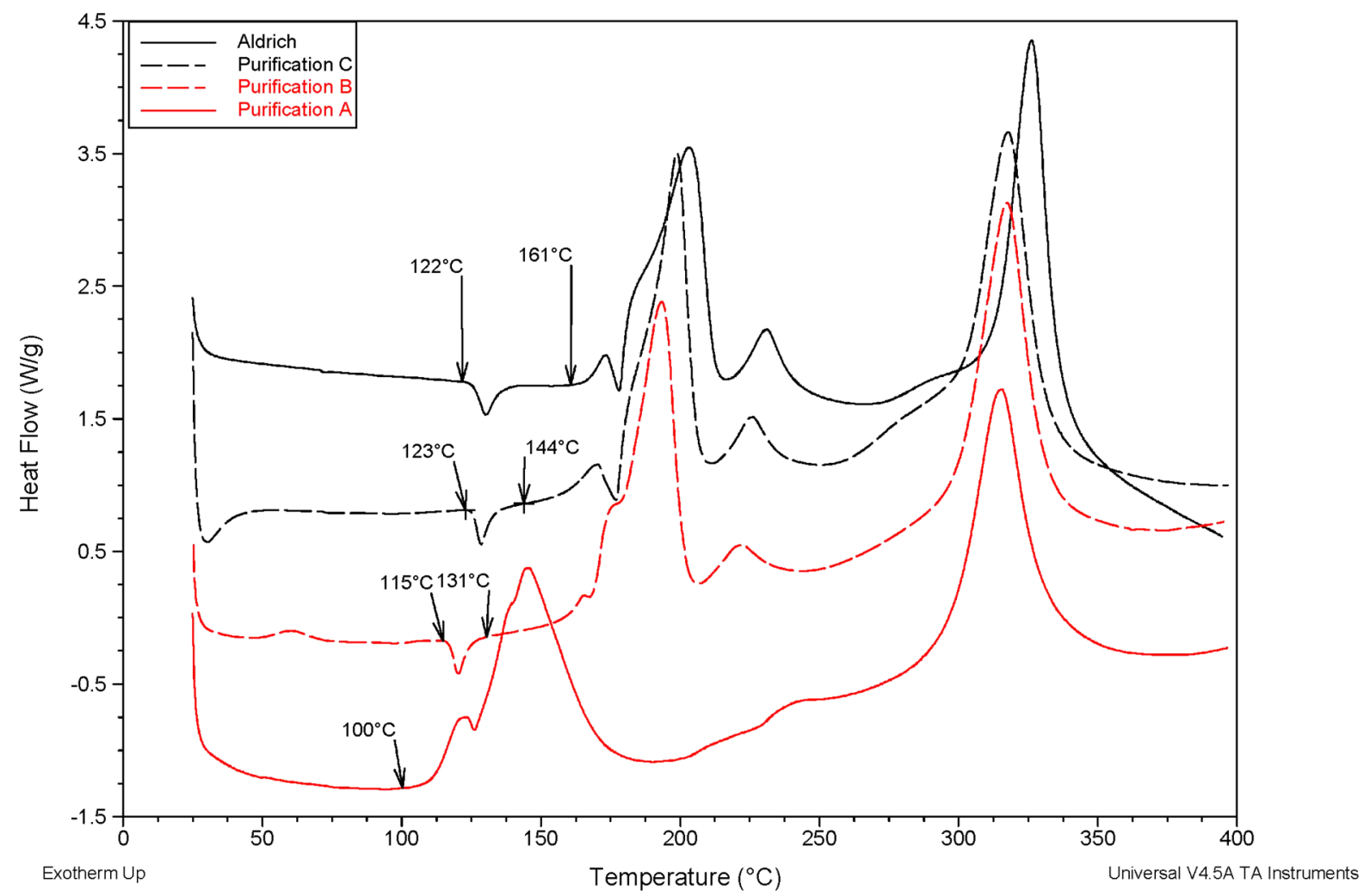

Figure 1. DSC thermograms for TIPS-EBX (1) referenced to Aldrich lot BGBC0627 V.

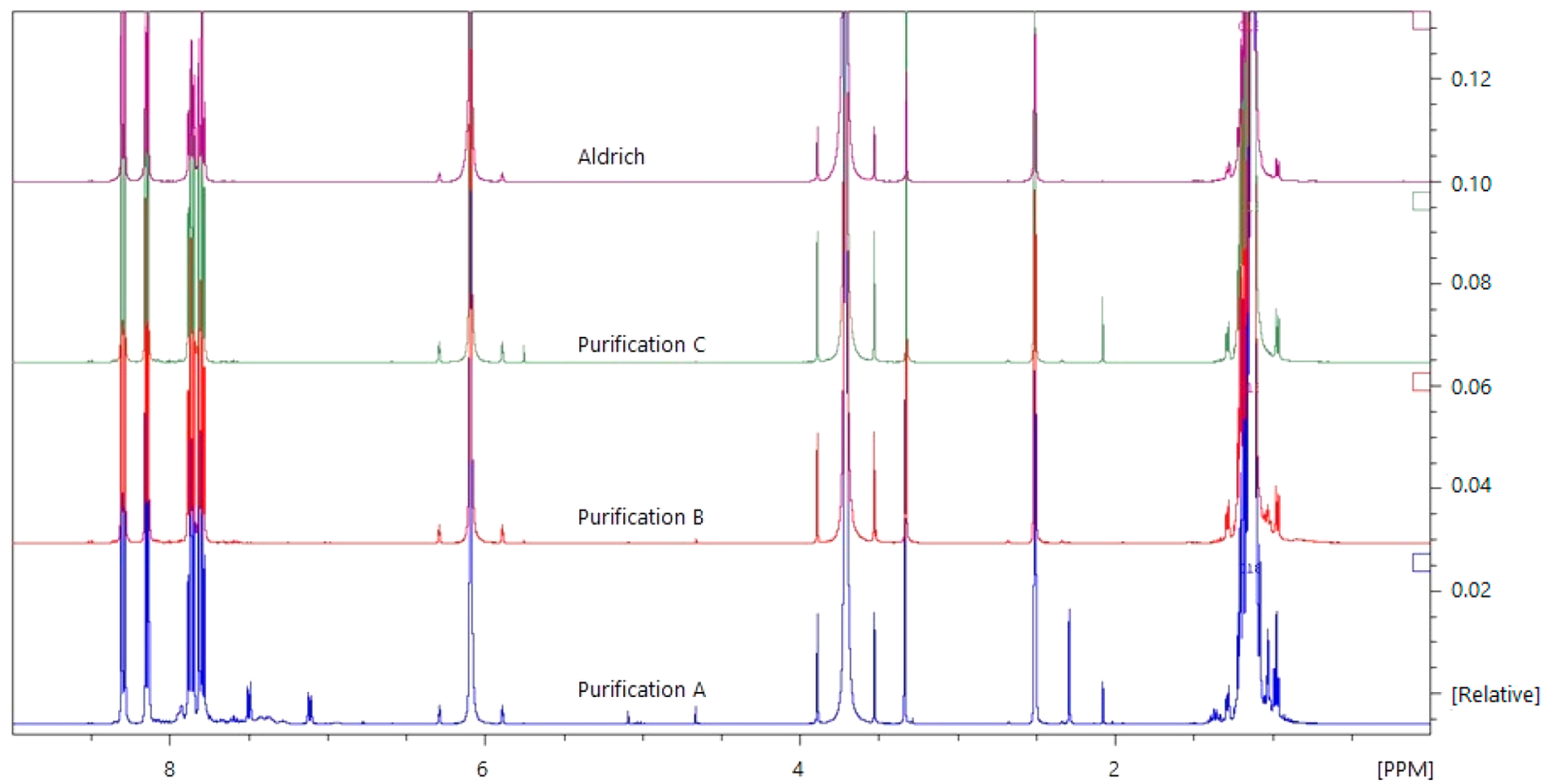

Figure 2. ${ }^{1} \mathrm{H}$ NMR spectra for TIPS-EBX (1) referenced to Aldrich lot BGBC0627 V.

reaction time, which is compounded with the lower sensitivity of DSC. So the onset temperature by DSC in this scanning mode should be considered $50-100{ }^{\circ} \mathrm{C}$ above the actual exotherm initiation temperature. The DSC uses a small (mg) sample size, and the detectable temperature/heat flow change by DSC achieves a sensitivity of ca. $5 \mathrm{~W} / \mathrm{kg}$. A more accurate measure of the actual exotherm initiation temperature will be made with an adiabatic calorimeter on several grams of sample, where the sensitivity is below $1 \mathrm{~W} / \mathrm{kg}$ depending on the conditions of the experiment.

So, with the DSC onset temperatures measured at 135-160 ${ }^{\circ} \mathrm{C}$, we recommend that the TIPS-EBX solids should not be heated above $50{ }^{\circ} \mathrm{C}$ without further testing to gain a better understanding of the actual initiation of the decomposition exotherm. Researchers should also recognize the potential for the walls of an oven, for example, to heat a portion of a sample 
Table 2. Summary of DSC Results for TIPS-EBX (1)

\begin{tabular}{cccccc} 
Entry & Sample & $\begin{array}{c}\text { Purity } \\
(\%)\end{array}$ & $\begin{array}{c}\text { Onset } \\
\text { Temperature } \\
\left({ }^{\circ} \mathrm{C}\right)\end{array}$ & $\begin{array}{c}\text { Total Energy } \\
(\mathrm{J} / \mathrm{g})\end{array}$ & $\begin{array}{c}\text { Impurity } \\
\text { level }(\%)\end{array}$ \\
1 & $\mathbf{A}$ & 91.8 & 100 & 1460 & 8.2 \\
2 & $\mathbf{B}$ & 97.8 & 130 & 1405 & 2.2 \\
3 & $\mathbf{C}$ & 99.2 & 134 & 1495 & 0.8 \\
4 & $\mathbf{C}^{a}$ & 99.2 & 144 & 1400 & 0.8 \\
5 & $\mathbf{D}$ & 99.9 & 161 & 1447 & 0.1 \\
6 & $\mathbf{D}^{a}$ & 99.9 & 150 & 1372 & 0.1 \\
${ }^{a}$ After & 4 month storage at $-20{ }^{\circ} \mathrm{C}$. \\
\multicolumn{5}{l}{}
\end{tabular}

to a temperature that might initiate the exotherm locally where solids contact the container that touches the oven wall.

Because the total energy release is high upon thermal degradation of TIPS-EBX (1), and the exotherm initiates at ranges of $134-144{ }^{\circ} \mathrm{C}$ for our samples and $150-160{ }^{\circ} \mathrm{C}$ for the sample from Aldrich, we carried out tests to examine the impact sensitivity of solid TIPS-EBX (1). The sample $\mathbf{C}$ and the Aldrich sample (D) both tested negative in 3 repeats at 25 $\mathrm{J}$ impact, so there is no evidence of the purified solid being potentially explosive or propagating an explosion.

In conclusion, we have reported a new one-step protocol for the synthesis of TIPS-EBX (1) requiring only commercially available reagents. From the three synthetic steps (oxidation, alkynylation, and cyclization), only oxidation and cyclization are slightly exothermic, resulting in an adiabatic temperature rise smaller than $15{ }^{\circ} \mathrm{C}$ at the used concentration. TIPS-EBX (1) obtained using our protocol is not shock-sensitive and has the same thermal stability as when accessed using previous methods. However, care has to be taken to carefully remove tosylate impurities, as they lead to lower decomposition temperatures.

\section{EXPERIMENTAL SECTION}

Synthesis of TIPS-EBX (1). A $250 \mathrm{~mL}$, three-necked, round-bottomed flask was equipped with a Teflon-coated magnetic stirrer $(2 \mathrm{~cm}$ ), a Liebig reflux condenser (open to air), and a septum. The septum was removed, and the flask was charged with $o$-iodobenzoic acid (2) $(6.00 \mathrm{~g}, 24.2 \mathrm{mmol}, 1.00$ equiv), $p$-toluenesulfonic acid monohydrate (4.60 g, 24.2 mmol, 1.00 equiv), 1,2-dichloroethane $(36.3 \mathrm{~mL})$, and trifluoroethanol $(36.3 \mathrm{~mL})$. The resulting white suspension was stirred $(600 \mathrm{rpm})$ at room temperature. $m \mathrm{CPBA}(\leq 77 \%$ purity; $5.96 \mathrm{~g}, 26.6 \mathrm{mmol}, \leq 1.10$ equiv $)^{25}$ was added in portions over a period of $10 \mathrm{~min}$. During the addition, the suspension slightly darkened, becoming beige. After the addition of $m \mathrm{CPBA}$, the septum was replaced, and the flask was placed in dry-sin preheated to $55{ }^{\circ} \mathrm{C}$ and stirred (600 $\mathrm{rpm})$. The mixture turned from a white suspension to a clear yellow color solution over a period of $5 \mathrm{~min}$. After $1.5 \mathrm{~h}$, (triisopropylsilyl)acetylene (7.60 mL, $33.9 \mathrm{mmol}, 1.40$ equiv) was added dropwise via a $10 \mathrm{~mL}$ syringe over a period of $5 \mathrm{~min}$ and stirring was continued at $55^{\circ} \mathrm{C}$ for another $24 \mathrm{~h}$. After this time, the pale-yellow solution was allowed to cool down to room temperature. Saturated aq. $\mathrm{NaHCO}_{3}(120 \mathrm{~mL})$ was then added: a pinkish mixture was formed with significant bubbling. This biphasic mixture was stirred $(1000 \mathrm{rpm})$ at room temperature for $1 \mathrm{~h}$. The mixture was transferred to a 250 $\mathrm{mL}$ separatory funnel, and the reaction flask was rinsed with dichloromethane $(12 \mathrm{~mL})$. The two layers were separated, and the aqueous layer was extracted with additional portions of dichloromethane $(3 \times 40 \mathrm{~mL})$. The combined organic layers were washed with water $(3 \times 50 \mathrm{~mL})$, prior to being dried over $\mathrm{MgSO}_{4}$ (ca. $3.0 \mathrm{~g}$ ), filtered into a $250 \mathrm{~mL}$ round-bottomed flask, and concentrated via rotary evaporation, ${ }^{24}$ to provide an off-white solid. The latter was purified by recrystallization from acetonitrile $(12 \mathrm{~mL})$ to provide TIPS-EBX (1) (8.36 g, 19.5 mmol, $81 \%$ yield) as a crystalline, white solid.

${ }^{1} \mathrm{H}$ NMR (400 MHz, $\left.\mathrm{CDCl}_{3}\right) \delta 8.42(\mathrm{dd}, J=5.9,3.2 \mathrm{~Hz}$, $1 \mathrm{H}, \mathrm{ArH}), 8.34-8.25$ (m, 1H, $\mathrm{ArH}), 7.80-7.72(\mathrm{~m}, 2 \mathrm{H}, \mathrm{ArH})$, 1.27-1.06 (m, 21H, TIPS).

${ }^{13} \mathrm{C} \mathrm{NMR}\left(101 \mathrm{MHz}, \mathrm{CDCl}_{3}\right) \delta 166.5,134.6,132.3,131.4$, $131.4,126.1,115.6,114.0,64.6,18.4,11.1$.

\section{ASSOCIATED CONTENT}

\section{Supporting Information}

The Supporting Information is available free of charge at https://pubs.acs.org/doi/10.1021/acs.oprd.9b00498.

General methods and additional figures (DSC and NMR spectra) (PDF)

\section{AUTHOR INFORMATION}

\section{Corresponding Author}

*E-mail: jerome.waser@epfl.ch.

ORCID $\odot$

Jerome Waser: 0000-0002-4570-914X

Notes

The authors declare no competing financial interest.

\section{ACKNOWLEDGMENTS}

We thank Ms. Marie-Madeleine Stempien and Ms. Katharina Gaus at Syngenta Crop Science in Stein, Switzerland for measuring the DSC of the sample synthesized in the Waser laboratory. We thank the Swiss National Science Foundation (No. 200021 159920), the European Research Council (ERC Starting Grant 334840), and EPFL for financial support.

\section{REFERENCES}

(1) Willgerodt, C. Zur Kenntniss aromatischer Jodidchloride, des Jodoso- und Jodobenzols. Ber. Dtsch. Chem. Ges. 1892, 25, 34943502.

(2) Yoshimura, A.; Zhdankin, V. V. Advances in Synthetic Applications of Hypervalent Iodine Compounds. Chem. Rev. 2016, $116,3328-3435$

(3) Li, Y.; Hari, D. P.; Vita, M. V.; Waser, J. Cyclic Hypervalent Iodine Reagents for Atom-Transfer Reactions: Beyond Trifluoromethylation. Angew. Chem., Int. Ed. 2016, 55, 4436-4454.

(4) Hari, D. P.; Caramenti, P.; Waser, J. Cyclic Hypervalent Iodine Reagents: Enabling Tools for Bond Disconnection via Reactivity Umpolung. Acc. Chem. Res. 2018, 51, 3212-3225.

(5) Ochiai, M.; Masaki, Y.; Shiro, M. Synthesis and Structure of 1Alkynyl-1,2-Benziodoxol-3(1H)-Ones. J. Org. Chem. 1991, 56, 55115513.

(6) Zhdankin, V. V.; Kuehl, C. J.; Krasutsky, A. P.; Bolz, J. T.; Simonsen, A. J. 1-(Organosulfonyloxy)-3(1H)-1,2-benziodoxoles: Preparation and Reactions with Alkynyltrimethylsilanes. J. Org. Chem. 1996, 61, 6547-6551.

(7) Hari, D. P.; Nicolai, S.; Waser, J. Alkynylations and Vinylations. PATAI'S Chemistry of Functional Groups; John Wiley \& Sons: 2018; p 1.

(8) Brand, J. P.; Charpentier, J.; Waser, J. Direct Alkynylation of Indole and Pyrrole Heterocycles. Angew. Chem., Int. Ed. 2009, 48, 9346-9349. 
(9) Feng, C.; Loh, T.-P. Rhodium-Catalyzed C-H Alkynylation of Arenes at Room Temperature. Angew. Chem., Int. Ed. 2014, 53, 27222726.

(10) Xie, F.; Qi, Z.; Yu, S.; Li, X. Rh(III)- and Ir(III)-Catalyzed C$\mathrm{H}$ Alkynylation of Arenes under Chelation Assistance. J. Am. Chem. Soc. 2014, 136, 4780-4787.

(11) Collins, K. D.; Lied, F.; Glorius, F. Preparation of Conjugated 1,3-Enynes by $\mathrm{Rh}(\mathrm{III})$-Catalysed Alkynylation of Alkenes via $\mathrm{C}$ - $\mathrm{H}$ Activation. Chem. Commun. 2014, 50, 4459-4461.

(12) Nicolai, S.; Erard, S.; Gonzalez, D. F.; Waser, J. Pd-Catalyzed Intramolecular Oxyalkynylation of Alkenes with Hypervalent Iodine. Org. Lett. 2010, 12, 384-387.

(13) Fernandez Gonzalez, D.; Brand, J. P.; Waser, J. Ethynyl-1,2benziodoxol-3 $(1 H)$-one (EBX): An Exceptional Reagent for the Ethynylation of Keto, Cyano, and Nitro Esters. Chem. - Eur. J. 2010, 16, 9457-9461.

(14) Aubineau, T.; Cossy, J. Chemoselective Alkynylation of NSulfonylamides Versus Amides and Carbamates-Synthesis of Tetrahydropyrazines. Chem. Commun. 2013, 49, 3303-3305.

(15) Frei, R.; Wodrich, M. D.; Hari, D. P.; Borin, P. A.; Chauvier, C.; Waser, J. Fast and Highly Chemoselective Alkynylation of Thiols with Hypervalent Iodine Reagents Enabled Through a Low Energy Barrier Concerted Mechanism. J. Am. Chem. Soc. 2014, 136, 16563-16573.

(16) Liu, X.; Wang, Z.; Cheng, X.; Li, C. Silver-Catalyzed Decarboxylative Alkynylation of Aliphatic Carboxylic Acids in Aqueous Solution. J. Am. Chem. Soc. 2012, 134, 14330-14333.

(17) Le Vaillant, F.; Courant, T.; Waser, J. Room-Temperature Decarboxylative Alkynylation of Carboxylic Acids Using Photoredox Catalysis and EBX Reagents. Angew. Chem., Int. Ed. 2015, 54, 1120011204.

(18) Hari, D. P.; Waser, J. Copper-Catalyzed Oxy-Alkynylation of Diazo Compounds with Hypervalent Iodine Reagents. J. Am. Chem. Soc. 2016, 138, 2190-2193.

(19) Fernández González, D.; Brand, J. P.; Mondière, R.; Waser, J. Ethynylbenziodoxolones (EBX) as Reagents for the Ethynylation of Stabilized Enolates. Adv. Synth. Catal. 2013, 355, 1631-1639.

(20) Brand, J. P.; Waser, J. Synthesis of 1- (Triisopropylsilyl)ethynyl $-1 \lambda(3), 2$-benziodoxol-3(1H)-one and Alkynylation of Indoles, Thiophenes, and Anilines. Synthesis 2012, 44, 1155-1158.

(21) Bouma, M. J.; Olofsson, B. General One-Pot Synthesis of Alkynyliodonium Salts and Alkynyl Benziodoxolones from Aryl Iodides. Chem. - Eur. J. 2012, 18, 14242-14245.

(22) This protocol can also be used with aryl- or alkyl-substituted terminal alkynes instead of triisopropylsilylacetylene. However, in this case lower yields are often obtained compared to using silyl or boronic ester substituted alkynes as starting materials. We speculate that this lower yield is due to the decreased stability of alkyl- or arylsubstituted EBX reagents upon prolonged heating.

(23) Performed by Ms. Marie-Madeleine Stempien and Ms. Katharina Gaus at Syngenta Crop Science in Stein, Switzerland on the sample of TIPS-EBX (1) synthesized in the Waser laboratory.

(24) To avoid evaporation to dryness, distillation of the reaction solvents with continuous addition of acetonitrile can also be used.

(25) The exact amount of $m$ CPBA can be obtained by titration and is usually between $70 \%$ and $77 \%$, corresponding to 1.0 to 1.1 equiv of reagent. In principle, only an equimolar amount of reagent is needed. 


\section{Supporting Information}

\section{General Methods}

For the experimental procedure described in the main part, following chemicals were used: 2iodobenzoic acid (98\% pure, TCI I0053-500G), triisopropylsilyl acetylene (95\% pure, Apollo, APOOR30591-25g), 3-chloroperbenzoic acid ( $\leq 77 \%$ pure, Sigma, 273031-100g, not titrated) and $p$-toluenesulfonic acid monohydrate (99\% pure, Acros 12902-5000). Analytical grade solvents were used. ${ }^{1} \mathrm{H}-\mathrm{NMR}$ spectra measured at EPFL were recorded on a Brucker DPX-400 $400 \mathrm{MHz}$ spectrometer in chloroform- $d$, all signals are reported in ppm with the internal chloroform signal at $7.26 \mathrm{ppm}$. The data is being reported as $(\mathrm{s}=$ singlet, $\mathrm{d}=$ doublet, $\mathrm{t}=$ triplet, $\mathrm{q}=$ quadruplet, $\mathrm{qi}=$ quintet, $\mathrm{m}=$ multiplet or unresolved, brs = broad signal, $\mathrm{app}=$ apparent, coupling constant(s) in $\mathrm{Hz}$, integration, interpretation). ${ }^{13} \mathrm{C}-\mathrm{NMR}$ spectra were recorded with ${ }^{1} \mathrm{H}$-decoupling on a Brucker DPX-400 $100 \mathrm{MHz}$ spectrometer in chloroform-d, all signals are reported in ppm with the internal chloroform signal at $77.0 \mathrm{ppm}$. DSCs were measured at Syngenta Crop Science AG on a Mettler Toledo DSC3 using high pressure gold plated $40 \mathrm{~mL}$ crucibles. Approximately $4 \mathrm{mg}$ of substance were precisely weighted to the microgram on a Mettler Toledo XPE56 balance into the DSC crucible. The sealed DSC crucible weight was measured with the same precision and recorded. The DSC crucible was then placed into the DSC oven and subjected to a temperature ramp from $-10^{\circ} \mathrm{C}$ to $450^{\circ} \mathrm{C}$ with a gradient of $4^{\circ} \mathrm{C}$ per minute. Integrations of endotherms and exotherms were performed using a linear baseline. After DSC measurement, the DSC crucible weight was checked to ensure that no weight loss had occurred during the DSC measurement.

DSC results reported in Figures 1, S3 and S4 and Table 2 were measured with a TA Instruments model Q200 differential scanning calorimeter. Samples of 3-5 mg were sealed in a SWISSI high-pressure M20 gold-plated crucible for analysis and sealed with an F11 ram. The samples in sealed crucibles were analyzed by scanning at $5{ }^{\circ} \mathrm{C} / \mathrm{min}$ from room temperature to $350{ }^{\circ} \mathrm{C}$. Results were analyzed using TA Universal Analysis software. 


\section{Supplementary Figures}

Figure S1. DSC spectrum of TIPS-EBX (1) measured at Syngenta Crop Science AG.

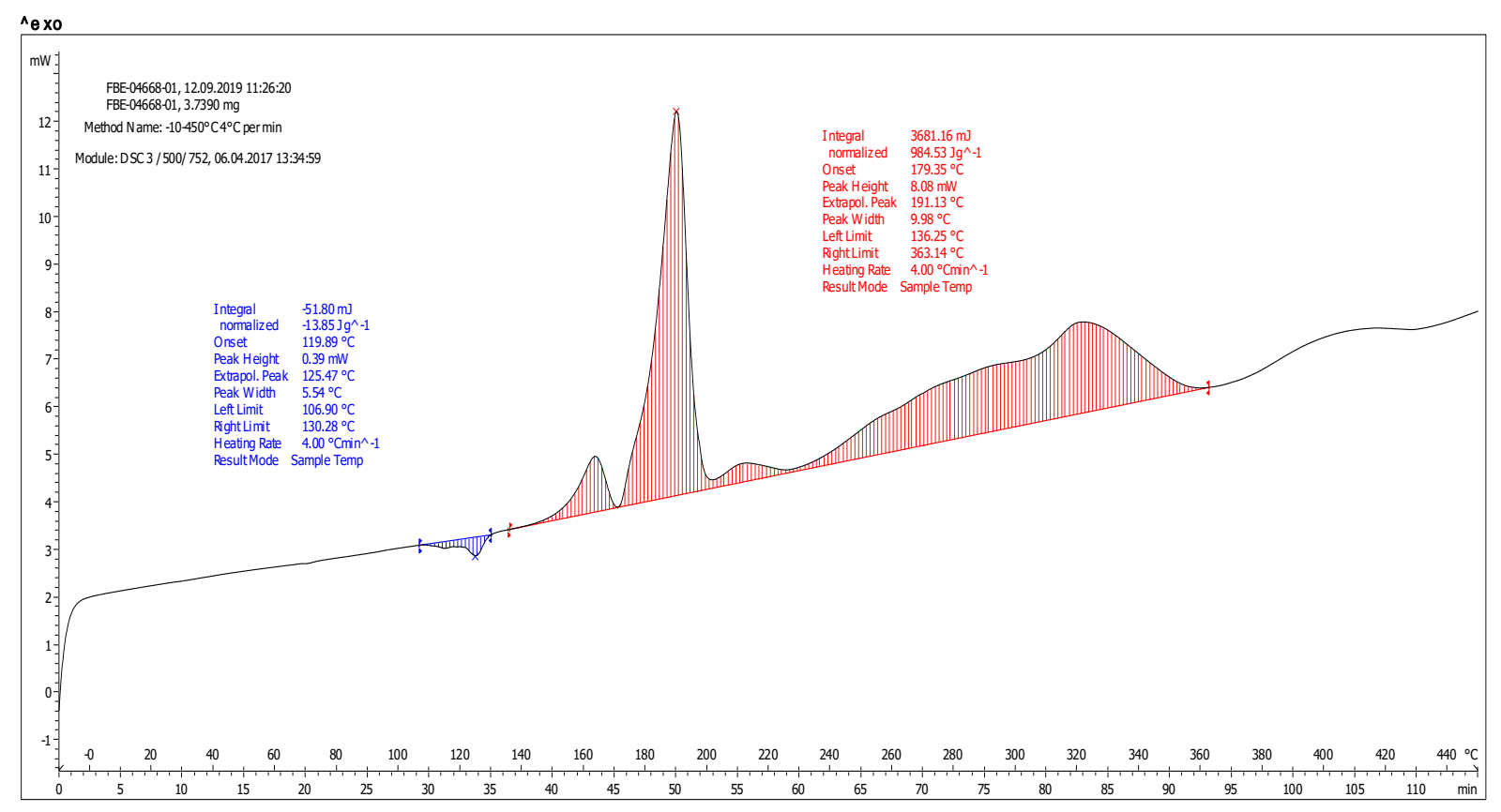

Figure S2. ${ }^{1} \mathrm{H}-\mathrm{NMR}$ and ${ }^{13} \mathrm{C}-\mathrm{NMR}$ spectra of the sample of TIPS-EBX (1) synthesized in the Waser Laboratory using crystallization from acetonitrile.
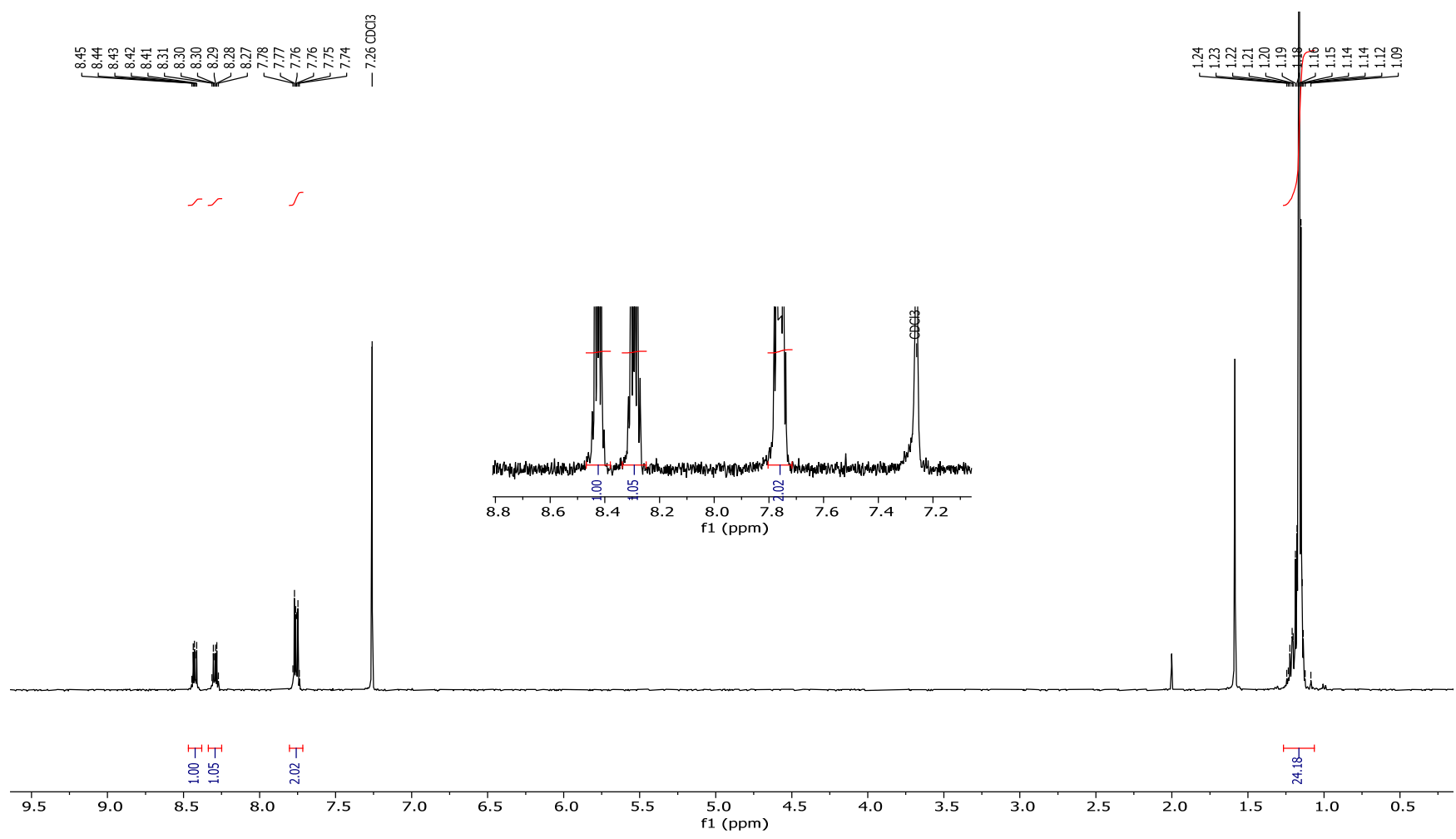


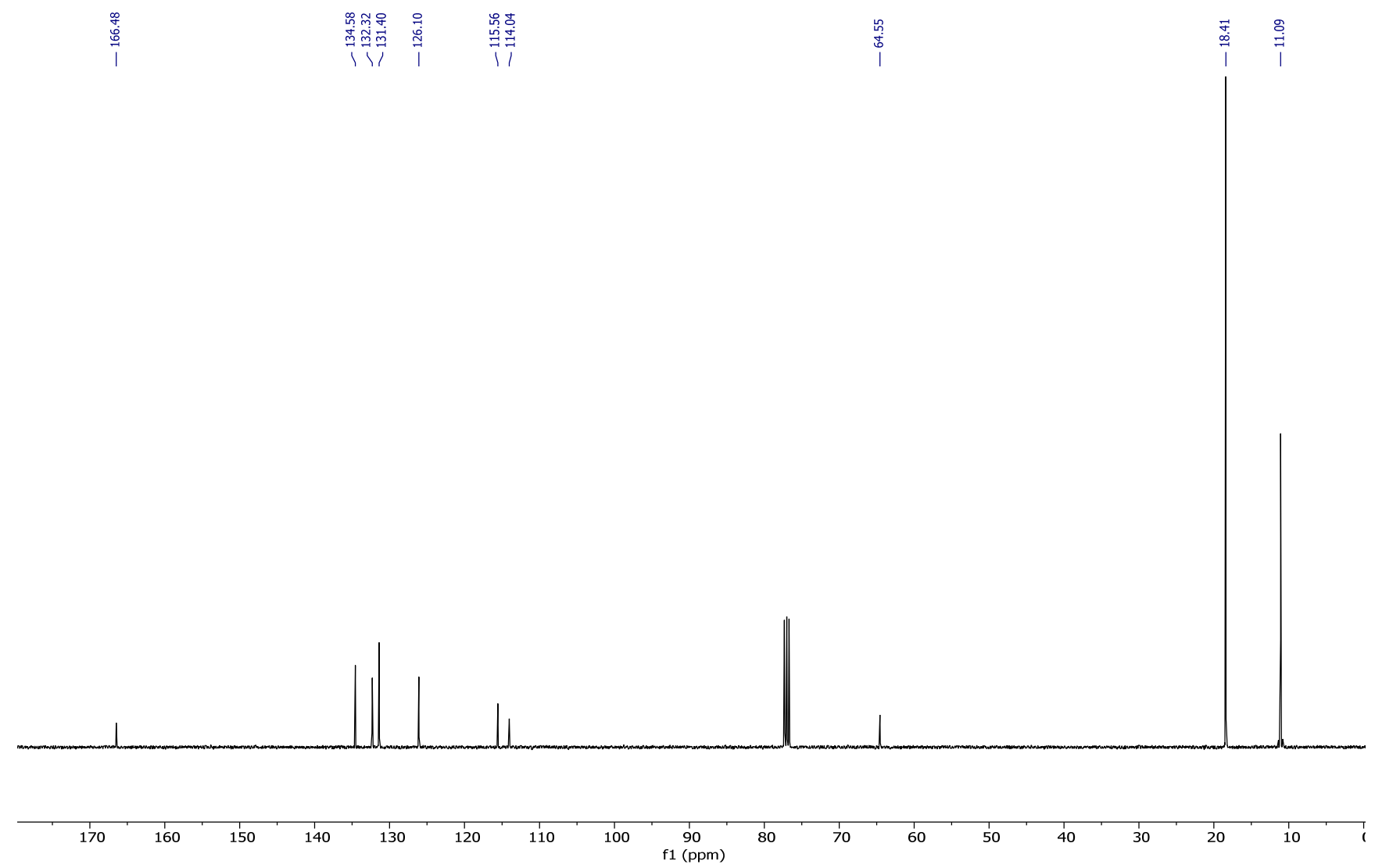


Figure S3. DSC spectra of the sample of TIPS-EBX (1) synthesized in the Merck laboratory measured directly after synthesis and after 4 months storage at $-20{ }^{\circ} \mathrm{C}$.

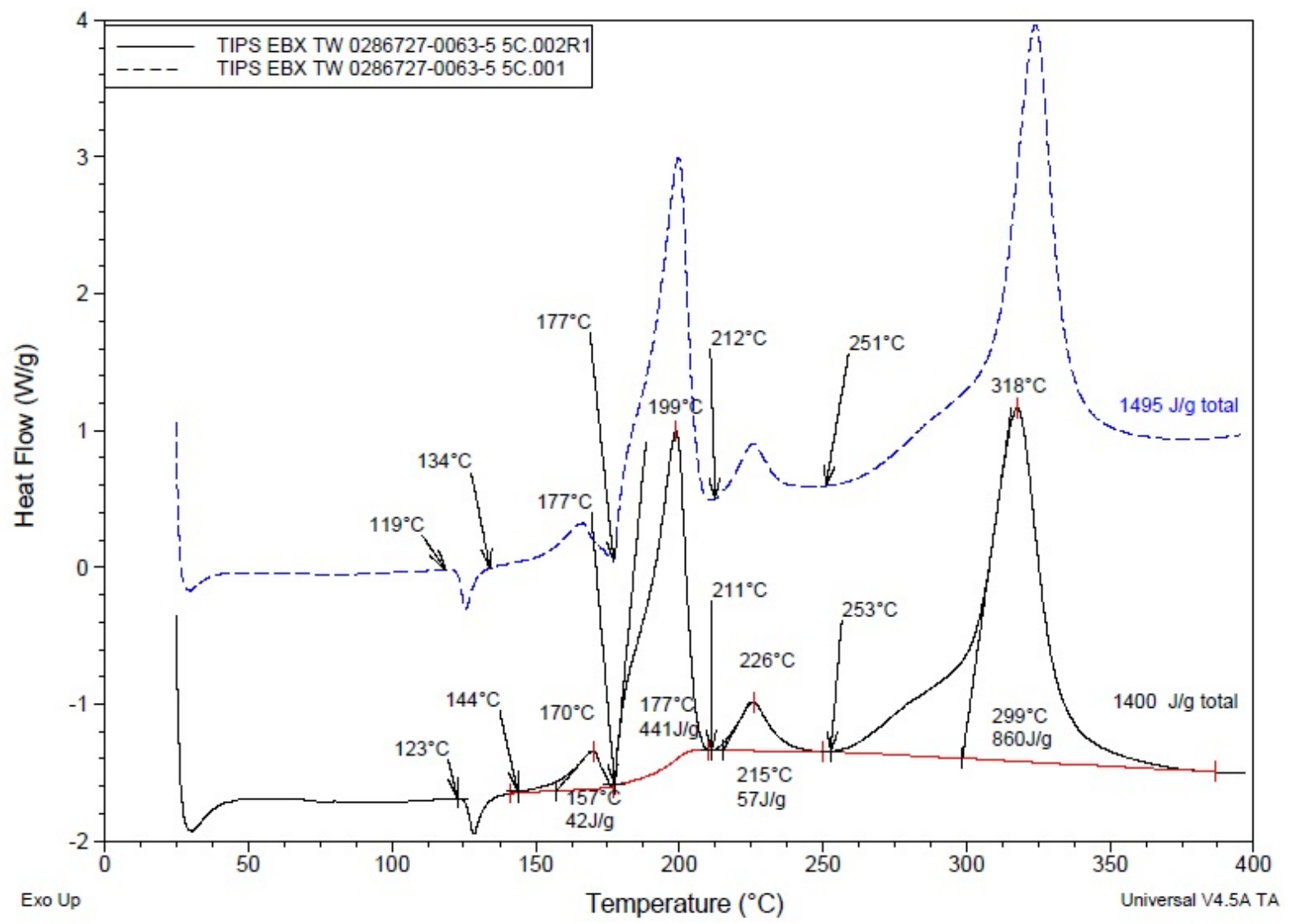


Figure S4. DSC spectra of the sample of TIPS-EBX (1) from Sigma-Aldrich batch BGBC0627V measured on December 2018 and on May 2019.

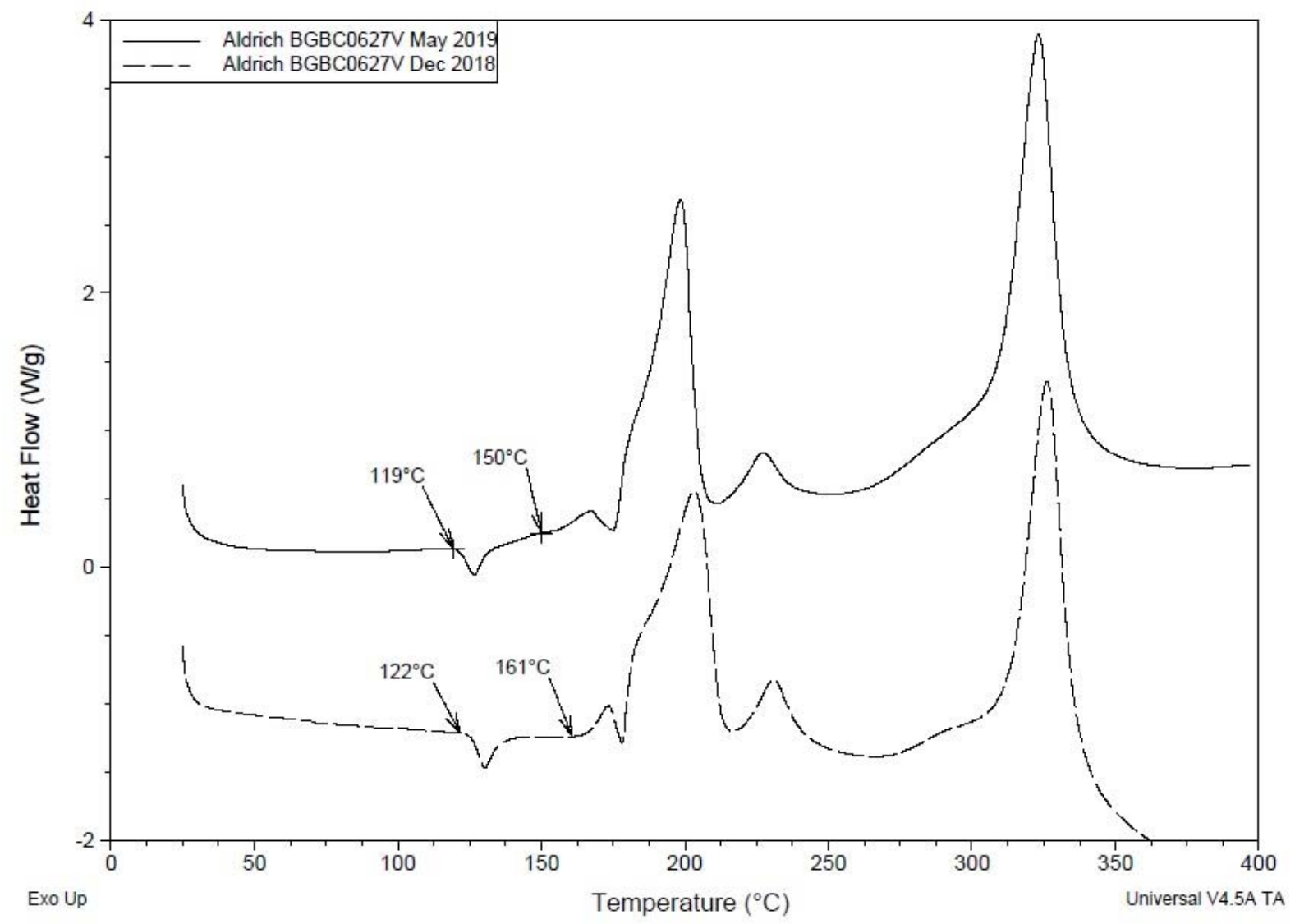

\section{Detailed experimental Procedure for the synthesis performed at Merck}

Materials: see above

Procedure:

To a Mettler Toledo EasyMax 102 100-mL vessel was charged 2-iodobenzoic acid (2) (6.00 g, $24.2 \mathrm{mmol}, 1.00$ equiv.), $p$-toluenesulfonic acid monohydrate (4.60 g, $24.2 \mathrm{mmol}, 1.00$ equiv.) dichloroethane $(36 \mathrm{~mL})$, and trifluoroethanol $(36 \mathrm{~mL})$. The resulting white suspension was agitated at room temperature. Next, $m \mathrm{CPBA}(6.33 \mathrm{~g}, 72.5 \mathrm{w} \%$ (according to titration), 26.6 mmol, 1.10 equiv) was added in portions over a total of 10 minutes. The slurry was heated to $55{ }^{\circ} \mathrm{C}$ over 30 minutes while stirring vigorously. 
The batch fully dissolved and was light brown by the time it reached $55{ }^{\circ} \mathrm{C}$, then turned light yellow over time. After 1.5 hours, (triisopropylsilyl)acetylene (6.18 g, 33.9 mmol, 1.40 equiv.) was added over 5 minutes, and then stirring was continued for 24 hours. Then, the solution was cooled to room temperature. $120 \mathrm{~mL}$ of saturated sodium bicarbonate was added and aged for 1 hour at $1000 \mathrm{rpm}$ with visible bubbling and foaming. The mixture was transfered to a 250$\mathrm{mL}$ separatory funnel, and the reactor was rinsed with $10 \mathrm{~mL}$ of dichloromethane which was also transfered to the separatory funnel. The 2 layers were separated, and then to the organic lower layer was added magnesium sulfate (18 g), which was stirred and then filtered to remove salt and bound water. The solids were washed with dichloromethane $(15 \mathrm{~mL})$ and the wash combined with the organic filtrate. The combined organics were concentrated to $15 \mathrm{~mL}$ using vacuum at $20{ }^{\circ} \mathrm{C}$, then dichloromethane $(60 \mathrm{~mL})$ was slowly added while maintaining a constant volume $(15 \mathrm{~mL})$ as the distillation was continued. Acetonitrile $(25 \mathrm{~mL})$ was added over 8 hours while the solution was stirred at $20^{\circ} \mathrm{C}$. The solution was concentrated from ca. 40 $\mathrm{mL}$ to ca. $30 \mathrm{~mL}$, then additional acetonitrile $(100 \mathrm{~mL})$ was added slowly. Crystallization of solids was observed when ca. $70 \mathrm{~mL}$ of acetonitrile was added. The slurry was stirred for 2 hours at $20^{\circ} \mathrm{C}$, then the solids were filtered and washed with acetonitrile $(12 \mathrm{~mL})$.

The wet solids were dried in vacuo at room temperature to provide TIPS-EBX (1) (7.73 g, 92 w\%, $16.8 \mathrm{mmol}, 69 \%$ yield).

To improve purity of the isolated TIPS-EBX (1) (denoted A) above, $100 \mathrm{mg}$ of the solid was added to $1 \mathrm{~mL}$ of dichloromethane; the mixture appeared as a dispersed fine slurry. The mixture was washed with water $(3 \times 1 \mathrm{~mL})$, then the organic layer was concentrated in vacuo at room temperature. This solid is denoted B and was observed to be $98 \mathrm{w} \%$ pure by NMR.

Separately, TIPS-EBX (1) (A, $1.5 \mathrm{~g}$ ) was dissolved in dichloromethane (15 mL), then washed with water $(3 \times 10 \mathrm{~mL})$. The organic layer was filtered through a $0.22 \mu \mathrm{m}$ filter and concentrated by rotary evaporator to ca. $5 \mathrm{~mL}$. Acetonitrile $(20 \mathrm{~mL})$ was added, and the mixture concentrated again to ca. $5 \mathrm{~mL}$ by rotary evaporation. Acetonitrile was added to bring the total volume to 10 $\mathrm{mL}$. The suspension was stirred at room temperature for 30 minutes, then solids were collected by filtration and washed with acetonitrile $(1 \mathrm{~mL})$. The purity of these solids designated $\mathbf{C}$ was found to be above $99 \%$ by NMR. 